\title{
Behaviorial inhibition and history of childhood anxiety disorders in Brazilian adult patients with panic disorder and social anxiety disorder Comportamento inibido e história de transtornos de ansiedade na infância em pacientes brasileiros adultos com transtorno do pânico e transtorno de ansiedade social
}

\section{Luciano Rassier Isolan, ${ }^{1,2}$ Cristian Patrick Zeni, ${ }^{1}$ Kelin Mezzomo, ${ }^{1}$ Carolina Blaya, ${ }^{1,2}$ Leticia Kipper,, Elizeth Heldt,, ${ }^{1,2}$ Gisele Gus Manfro ${ }^{1,2}$}

\author{
Original version accepted in English
}

\begin{abstract}
Purpose: To evaluate the presence of behavioral inhibition and anxiety disorders during childhood in Brazilian adult patients with panic disorder and social anxiety disorder compared to a control group. Methods: Fifty patients with panic disorder, 50 patients with social anxiety disorder, and 50 control subjects were included in the study. To assess the history of childhood anxiety, the Schedule for Affective Disorders and Schizophrenia for School Age Children, Epidemiologic Version (K-SADS-E), and the Diagnostic Interview for Children and Adolescents-Parent Version (DICA-P) were used. The presence of behavioral inhibition in childhood was assessed by the self-reported scale of Behavioral Inhibition Retrospective Version (RSRI-30). Results: Patients showed significantly higher prevalence of anxiety disorders and behavioral inhibition in childhood compared to the control group. Patients with social anxiety disorder also showed significantly higher rates of avoidance disorder (46\% vs. 18\%, $p=0.005)$, social anxiety disorder (60\% vs. 26\%, $p=0.001)$, presence of at least one anxiety disorder (82\% vs. 56\%, p = 0.009) and global behavioral inhibition ( $2.89 \pm 0.61$ vs. $2.46 \pm 0.61, p<0.05)$ and school/social behavioral inhibition (3.56 \pm 0.91 vs. $2.67 \pm$ 0.82, $p<0.05$ ) in childhood compared to patients with panic disorder. Conclusion: Our data are in accordance to the literature and corroborates the theory of an anxiety diathesis, suggesting that a history of anxiety disorders in childhood is associated with an anxiety disorder diagnosis, mainly social anxiety disorder, in adulthood.
\end{abstract}

Keywords: Panic disorder; Anxiety disorder; Inhibition (psychology); Phobic disorders; Child

\section{Resumo}

Objetivos: Avaliar a presença de história de comportamento inibido e de transtornos de ansiedade na infância em pacientes brasileiros adultos com transtorno do pânico e com transtorno de ansiedade social, comparando-os com um grupo controle. Métodos: Cinqüenta pacientes com transtorno do pânico, 50 com transtorno de ansiedade social e 50 controles participaram do estudo. Para avaliar a presença de história de ansiedade na infância foi utilizada a Escala para Avaliação de Transtornos Afetivos e Esquizofrenia para Crianças em Idade Escolar - Versão Epidemiológica (K-SADS-E) e o Diagnostic Interview for Children and Adolescents-Parent Version (DICA-P). A presença de comportamento inibido na infância foi avaliada através da Escala AutoAplicativa de Comportamento Inibido - Versão Retrospectiva (RSR/-30). Resultados: Os pacientes apresentavam uma prevalência significativamente maior de história de transtornos de ansiedade e de comportamento inibido em relação ao grupo controle. Pacientes com transtorno de ansiedade social apresentavam, também, taxas significativamente maiores de transtorno de evitação $(46 \% \times 18 \%, p=0,005)$, transtorno de ansiedade social $(60 \% \times 26 \%, p=0,001)$, presença de pelo menos um transtorno de ansiedade na infância ( $82 \% \times 56 \%, p=0,009)$, comportamento inibido global $(2,89 \pm 0,61$ vs. 2,46 \pm 0,61, p < 0,05) e comportamento inibido escola/social (3,56 $\pm 0,91$ vs. 2,67 $\pm 0,82, p<0.05)$ na infância em comparação com pacientes com transtorno do pânico. Conclusão: Nossos dados são similares aos encontrados na literatura e corroboram a teoria da diátese de ansiedade, sugerindo que a história de transtornos de ansiedade na infância é associada com transtornos de ansiedade, principalmente transtorno de ansiedade social, na vida adulta.

Descritores: Transtorno do pânico; Transtornos de ansiedade; Inibição (psicológica); Transtornos fóbicos; Criança

\footnotetext{
1 Anxiety Disorders Program of the Psychiatric Service of the Hospital de Clínicas de Porto Alegre (Clinical Hospital of Porto Alegre), Porto Alegre, RS, Brazil

2 Post-graduate Program in Medical Sciences: Psychiatry of the Universidade Federal do Rio Grande do Sul (UFRGS, Federal University of Rio Grande do Sul)

Financing: None

Conflict of interests: None

Submitted: 21 September 2004

Accepted: 2 February 2005

Correspondence

Gisele Gus Manfro

R. Luiz Manoel Gonzaga 630 / 11

90470-280 Porto Alegre, RS, Brasil

E-mail: gmanfro@portoweb.com.br
} 


\section{Introduction}

Since anxiety disorders are the most prevalent form of psychopathology in children and adolescents, early indicators of anxiety, such as behavioral inhibition, demand particular attention. ${ }^{1}$ Studies assessing familiar patterns and retrospective studies in adults with anxiety disorders have described an association between behavioral inhibition and anxiety disorders in childhood and adulthood psychopathology. ${ }^{2}$ Several studies show a high rate of anxiety disorders in the offspring of adult patients with anxiety disorders, ${ }^{3-7}$ and in parents of children with behavioral inhibition and anxiety disorders. ${ }^{8-9}$ Retrospective reports of adults with anxiety disorders suggest that anxiety disorders are highly prevalent in childhood and may influence the presentation and the development of anxiety disorders in adulthood. ${ }^{10-13}$ At first, a study by Klein ${ }^{14}$ proposed that separation anxiety disorder was specifically associated with the development of panic disorder and agoraphobia. However, later studies showed that other childhood anxiety disorders, besides separation anxiety disorder, were common in retrospective reports of patients with panic disorder, and that separation anxiety disorder was also related to other anxiety disorders in adulthood. Lipsitz et al, ${ }^{10}$ evaluated 252 adult outpatients with anxiety disorders, and observed that the prevalence of separation anxiety disorder did not differ between patients with panic disorder, social anxiety disorder and obsessive-compulsive disorder. Moreover, according to this author, the presence of this condition in childhood was associated with higher rates of comorbidities with anxiety disorders in adulthood.

Several studies have also demonstrated the association between temperament and anxiety, mood, disruptive and attention-deficit/hyperactivity disorder. ${ }^{15}$ Behavioral inhibition, which is present in 10 to $15 \%$ of children, is characterized by behavioral components such as social withdrawal and physiological components such as the increase of salivary cortisol level, urinary catecholamines level, heart rate, and the pupillary dilation. ${ }^{16}$ This temperament hypothetically reflects a lower threshold to limbic excitability and sympathetic activation, specifically, higher reactivity of the basolateral and central nuclei of the amygdale and their projections to the striatum, hypothalamus, sympathetic chain, and cardiovascular system. ${ }^{16}$ Studies show that children whose parents have a diagnosis of panic disorder/agoraphobia, with or without major depression, presented significantly higher rates of behavioral inhibition than children of psychiatric controls without panic disorder/agoraphobia or without major depression, and that parents of children with behavioral inhibition showed higher rates of anxiety disorders compared to parents of children without behavioral inhibition, suggesting behavioral inhibition is linked to a familiar predisposition to anxiety disorders. ${ }^{17}$ Hirshfeld et al $^{18}$ demonstrated that children who remained inhibited throughout childhood would be at increased risk of anxiety disorder as compared as children who were not persistently inhibited. Their results suggest that the presence of stable behavioral inhibition seems to be a strong predictor of anxiety disorder. Retrospective and prospective studies have shown that the presence of behavioral inhibition is associated with higher rates of anxiety disorders in adulthood, supporting, thus, the diathesis theory. ${ }^{19-23}$

In Brazil, there are no studies accessing the presence of anxiety disorders and behavioral inhibition in childhood as well as their influence in clinical features, course, and prognosis of anxiety disorders in adulthood. The aim of this study was to evaluate the presence of a childhood history of anxiety and behavioral inhibition in adult patients with panic disorder, and social anxiety disorder, compared to a control group in Southern Brazil.

\section{Methods}

Consecutive adult patients from the Anxiety Disorders Program of the Psychiatric Service of the Clinical Hospital of Porto Alegre, which met full DSM-IV24 criteria for panic disorder and social anxiety disorder were included in this study. Subjects were in different stages of the treatment, with or without comorbidity with other psychiatric disorders. Patients with past or present diagnosis of schizophrenia or other psychotic disorders were excluded. The control group was composed by employees of the Clinical Hospital of Porto Alegre, without psychiatric disorders, who were invited to participate in the study during their annual medical check-up.

All patients and controls gave their informed consent in written and no patient refused to participate in the study. The project was approved by the Human Ethics Committee of the Clinical Hospital of Porto Alegre. All subjects were evaluated by clinical interview and by the M.I.N.I. (Mini International Neuropsychiatric Interview - Brazilian Version 5.0 - DSMIV), ${ }^{25-26}$ a standardized structured diagnostic interview which evaluates the main Axis I Psychiatric disorders, according to the DSM-IV criteria. History of childhood anxiety disorders was assessed using the Schedule for affective disorders and schizophrenia for school-age children, Epidemiological Version (K-SADS-E), ${ }^{27}$ which evaluates the following disorders: separation anxiety; generalized anxiety; phobic disorders, subdivided into agoraphobia and social anxiety disorder. In order to evaluate the presence of avoidance disorder, the Diagnostic Interview for Children and Adolescents- Parents Version (DICA-P) ${ }^{28}$ was used. The Self-Report Scale of

Table 1 - Frequency of childhood anxiety disorders

\begin{tabular}{|c|c|c|c|c|}
\hline & $\begin{array}{l}\text { Control } \\
(n=50)\end{array}$ & $\begin{array}{l}\text { Social anxiety disorder } \\
\qquad(n=50)\end{array}$ & $\begin{array}{l}\text { Panic disorder } \\
(n=50)\end{array}$ & $p=$ \\
\hline Separation anxiety disorder & $3(6.0 \%)$ & $19(38.0 \%)^{*}$ & $20(40.0 \%)^{\star}$ & $<0.001$ \\
\hline Generalized anxiety disorder & $4(8.0 \%)$ & $25(50 \%)^{\star}$ & $18(36.0 \%)^{*}$ & $<0.0001$ \\
\hline Avoidance disorder & $5(10.0 \%)$ & $23(46.0 \%)^{\star} \#$ & $9(18.0 \%)^{\star}$ & $<0.0001$ \\
\hline Agoraphobia & $3(6.0 \%)$ & $14(28.0 \%)^{\star}$ & $8(16.0 \%)$ & $<0.05$ \\
\hline Social anxiety disorder & $7(14.0 \%)$ & $30(60.0 \%)^{*} \#$ & $13(26.0 \%)^{*}$ & $<0.0001$ \\
\hline At least one disorder & $13(26.0 \%)$ & $41(82.0 \%)^{\star} \#$ & $28(56.0 \%)^{\star}$ & $<0.0001$ \\
\hline Two or more disorders & $6(12.0 \%)$ & $33(66.0 \%)^{*} \#$ & $22(44.0 \%)^{*}$ & $<0.0001$ \\
\hline
\end{tabular}

Difference between the groups. Chi-Square test.

* Difference compared to the control group $(p<0.05)$. Multiple comparisons of proportions

\# Difference compared to the panic disorder group $(p<0.05)$. Multiple comparisons of proportions 
Behavioral Inhibition - Retrospective Version (RSRI) ${ }^{29}$ was used to assess childhood behavioral inhibition. The RSRI contains 30 items and has both a retrospective and a current version. The retrospective version, used in this study, asks subjects to answer the questions about themselves when they were in elementary school. When Reznick et al ${ }^{29}$ factor-analyzed their measure, the screen plot suggested a two-factor solution as the one providing the best description of the measure. The first factor consisted of items measuring social and school related fears, and the second factor consisted of items measuring general fearfulness and/or illness. These instruments were applied by independent evaluators blinded to the subject's diagnosis.

The statistical analysis was performed by the SPSS - Version 11.0 and PEPI version 3.0 software, using the chi-square test followed by multiple comparisons of proportions and Brown Forsythe followed by Dunnet test, considering a level of significance of 0.05 .

\section{Results}

The studied sample included 50 patients with panic disorder (34 women, and 16 men with a mean age of $39.6 \pm 9.34$ years), 50 patients with social anxiety disorder ( 25 women and 25 men with a mean age of $33.1 \pm 12.15$ years), and 50 controls (34 women and 16 men with a mean age of $36.8 \pm 7.91$ years). The sample did not differ regarding gender and age.

The frequencies of history of childhood anxiety disorders found in patients with panic disorder, social anxiety disorder, and the control group are described in Table 1. Table 2 depicts behavioral inhibition rates found in the three different groups.

Patients with anxiety disorders showed significantly higher rates of childhood anxiety disorders and behavioral inhibition when compared to the control group. Patients with social anxiety disorder presented significantly higher rates of history of avoidance disorder, social anxiety disorder, and the presence of one or more childhood anxiety disorders, as well as higher scores in the global score of behavioral inhibition, and in the School/Social sub-item when compared to panic disorder patients. The presence of behavioral inhibition was positively associated with the presence of anxiety disorders in childhood ( $<<0.05$ ).

\section{Discussion}

In this study, a higher prevalence of childhood history of anxiety, and higher levels of behavioral inhibition were found in Brazilian patients with anxiety disorders compared to the prevalences found the control group, being in accordance with the literature. ${ }^{10-13}$ Moreover, in agreement to other studies, patients with social anxiety disorder have also showed higher rates of anxiety disorder in childhood compared to panic patients. ${ }^{12}$ According to the anxiety diathesis theory ${ }^{19}$ there is

\section{Table 2 - Behavioral inhibition in childhood (mean \pm standart desviation)}

\begin{tabular}{lcccc}
\hline & $\begin{array}{c}\text { Control } \\
(\mathbf{n}=50)\end{array}$ & $\begin{array}{c}\text { Social anxiety } \\
\text { disorder } \\
(\mathbf{n}=50)\end{array}$ & $\begin{array}{c}\text { Panic } \\
\text { disorder } \\
(\mathbf{n}=50)\end{array}$ & $p^{*}$ \\
\hline Global & $1.92 \pm 0.47$ & $2.89 \pm 0.61^{*} \#$ & $2.46 \pm 0.61^{*}$ & $<0.001$ \\
School/Social & $2.27 \pm 0.71$ & $3.56 \pm 0.91^{*} \#$ & $2.67 \pm 0.82^{*}$ & $<0.001$ \\
Fears/Disease & $1.38 \pm 0.46$ & $2.22 \pm 0.73^{*}$ & $2.16 \pm 0.74^{*}$ & $<0.001$ \\
\hline
\end{tabular}

Difference between the groups. Analysis of Brown Forsythe

* Differences compared to the control group $(p<0.05)$. Dunnet test.

\# Differences compared to the group with panic disorder $(p<0.05)$. Dunnet test. a familiar background for anxiety since childhood which can be expressed in a different ways depending on the life cycle stage the subject is undergoing.

Patients with social anxiety disorder also presented significantly higher rates of social anxiety disorder and avoidance in childhood than patients with panic disorder did, which may suggest that the first manifestations of social anxiety disorder had already occurred in childhood. Moreover, patients with social anxiety disorder, as well as patients with panic disorder, presented higher global scores of behavioral inhibition (overall, school/social, fears/disease) than controls did, but a significant difference was found in the total score and in the factor school/social in patients with social anxiety disorder compared to patients with panic disorder. These data suggest that phobic patients were already more inhibited in school and social situations, than were patients with panic disorder.

These results found in our study are in accordance with previous data, which suggest that history of childhood anxiety history and behavioral inhibition are more associated with social anxiety disorder than with any other anxiety disorders in adulthood. ${ }^{20-23}$ Hayward et al ${ }^{22}$ performed the first prospective study assessing the role of behavioral inhibition in the development of social anxiety disorder during adolescence. That study, which followed 2242 students for 4 years, with a mean age of 15 years in the first evaluation, showed that, although childhood behavioral inhibition does not always become a social anxiety disorder in adolescence, the risk for social anxiety disorder in adolescence is possibly 4 to 5 -fold for those with childhood behavioral inhibition. The association between behavioral inhibition and social anxiety disorder was also described in a study by Schwartz et $\mathrm{al}^{23}$ which evaluated 79 adolescents in a semi-structured clinical interview, with a mean age of 13 years, from cohorts of previous studies, which had been classified as inhibited or non-inhibited in the second year of life. They showed that the presence of behavioral inhibition in childhood, mainly in females, was significantly associated with generalized social phobia, but not with specific phobias, separation anxiety, or performance anxiety in adolescence. Of the subjects with behavioral inhibition in childhood, $61 \%$ developed social anxiety disorder in adolescence, contrasting with the $27 \%$ classified as having non-behavioral inhibition. Biederman et $a^{30}$ found that behavioral inhibition in children was selectively associated with a higher risk for avoidant disorder and social anxiety disorder, mainly among children whose parents had had panic disorder either with or without depression. This suggests that parental panic disorder and child behavioral inhibition could be used to identify children at higher risk for social anxiety disorders. Using longitudinal data, Pine et $a^{31}$ prospectively examined the relationship between adolescent and early adulthood anxiety. Over the nine years study period, they found that adolescent anxiety disorders predicted roughly a twofold increase in risk for adult anxiety disorders. Their results suggest that although most adolescent anxiety disorders do not persist into adulthood, most adult disorders are preceded by an anxiety disorder in adolescence.

Patients with social anxiety disorder seem to have a childhood anxiety component much similar to that observed in adulthood. Avoidance disorders and social anxiety disorder in childhood are more related to social anxiety disorder in adulthood than panic disorder. Of note, the DSM-IV ${ }^{24}$ does not use the diagnosis of avoidance disorder, which was present previously in the DSM-III-R, ${ }^{32}$ and includes it in the social anxiety disorders. The 
data from the present study corroborate this change. These disorders seem to belong to the same spectrum and persist in lifetime.

In spite of the evident difference observed in the prevalence of childhood anxiety disorders in patients with anxiety disorders and controls, our study has the limitation of being retrospective, and thus it is possibly influenced by the individual's current mood. Although not all children with behavioral inhibition become anxious in the future, children with this temperament, mainly with parents with anxiety disorders and/or depressive disorders, may benefit from preventive or early strategies aiming to increase social abilities. Moreover, the efficacious treatment of the present childhood anxiety disorders could prevent the development of more severe forms of psychopathology in adulthood. This is important due to the very high prevalence of anxiety disorders in the Brazilian population ${ }^{33}$ and therefore a preventive treatment could reduce the morbidity in these people. These children's parents could be counseled about their offspring's temperament and anxiety symptoms that may be more amenable to some techniques and brief treatment. Prospective, controlled, long-lasting studies, focused in the detection of anxiety disorders in children, as well as in the follow-up of this population, could offer more robust data, which may allow the development of early intervention methods for children at risk. These studies might help to prevent and/ or decrease the morbidity of both anxiety and depressive disorders in adulthood.

\section{Conclusion}

The present study corroborates the theory of an anxiety diathesis, suggesting that a history of anxiety disorders in childhood is associated with an anxiety disorder diagnosis, mainly social anxiety disorder, in adulthood. Therefore, early intervention and treatment of childhood anxiety disorder might help to prevent and/or decrease the morbidity of both anxiety and depressive disorders in adulthood.

\section{References}

1. Castellanos D, Hunter T. Anxiety disorders in children and adolescents. South Med J. 1999;92(10):946-54.

2. Pollack $\mathrm{MH}$, Smoller JW. The longitudinal course and outcome of panic disorder. Psychiatr Clin North Am. 1995;18(4):785-801.

3. Berg I. School phobia in the children of agoraphobic women. $\mathrm{Br} \mathrm{J}$ Psychiatry. 1976;128:86-9.

4. Weissman MM, Leckman JF, Merikangas KR, Gammon GD, Prusoff BA. Depression and anxiety disorders in parents and children. Results from the Yale family study. Arch Gen Psychiatry. 1984;41(9):845-52.

5. Mancini C, van Ameringen M, Szatmari P, Fugere C, Boyle M. A high-risk pilot study of the children of adults with social phobia. J Am Acad Child Adolesc Psychiatry. 1996;35(11):1511-7.

6. Lieb R, Wittchen HU, Hofler M, Fuetsch M, Stein MB, Merikangas KR. Parental psychopathology, parenting styles, and the risk of social anxiety disorder in offspring: a prospective-longitudinal community study. Arch Gen Psychiatry. 2000;57(9):859-66.

7. Biederman J, Faraone SV, Hirshfeld-Becker DR, Friedman D, Robin JA, Rosenbaum JF. Patterns of psychopathology and dysfunction in high-risk children of parents with panic disorder and major depression. Am J Psychiatry. 2001;158(1):49-57.

8. Last CG, Hersen M, Kazdin A, Francis G, Grub HG. Psychiatric illness in the mothers of anxious children. Am J Psychiatry. 1987; 144(12):1580-3.

9. Last CG, Hersen M, Kazdin A, Orvaschel H, Perrin S. Anxiety disorders in children and their families. Arch Gen Psychiatry. $1991 ; 48(10): 928-34$

10. Lipsitz JD, Martin LY, Mannuzza S, Chapman TF, Liebowitz MR, Klein DF, et al. Childhood separation anxiety disorder in patients with adult anxiety disorders. Am J Psychiatry. 1994;151(6):927-9.
11. Pollack MH, Otto MW, Sabatino S, Majcher D, Worthington JJ, McArdle ET, et al. Relationship of childhood anxiety to adult panic disorder: correlates and influence on course. Am J Psychiatry. 1996;153(3):376-81.

12. Otto MW, Pollack MH, Maki KM, Gould RA, Worthington JJ 3rd, Smoller JW, et al. Childhood history of anxiety disorders among adults with social anxiety disorder: rates, correlates, and comparisons with panic disorder. Depress Anxiety. 2001;14(4):209-13.

13. Manfro GG, Isolan LR, Blaya C, Santos L, Silva MS. Estudo retrospectivo da associação entre transtorno de pânico em adultos e transtorno de ansiedade na infância. Rev Bras Psiquiatr. 2002;24(1):26-9.

14. Klein D. Delineation of two-drug responsive anxiety syndromes. Psychopharmacologia. 1964;17:397-408.

15. Hirshfeld-Becker DR, Biederman J, Calltharp S, Rosenbaum ED, Faraone SV, Rosenbaum JF. Behavioral inhibition and disinhibition as hypothesized precursors to psychopathology: implications for pediatric bipolar disorder. Biol Psychiatry. 2003;53(11):985-99.

16. Kagan J, Reznick JS, Snidman N. Biological bases of childhood shyness. Science. 1988;240(4849):167-71.

17. Rosenbaum JF, Biederman J, Hirshfeld DR, Bolduc EA, Chaloff J. Behavioral inhibition in children: a possible precursor to panic disorder or social phobia. J Clin Psychiatry. 1991;52 Suppl:5-9.

18. Hirshfeld DR, Rosenbaum JF, Biederman J, Bolduc EA, Faraone SV, Reznick JS, et al. Stable behavioral inhibition and its association with anxiety disorder. J Am Acad Child Adolesc Psychiatry. 1992;31(1):103-11.

19. Biederman J, Rosenbaum JF, Bolduc-Murphy EA, Faraone SF, Chaloff J, Hirshfeld DR, et al. A 3-year follow-up of children with and without behavioral inhibition. J Am Acad Child Adolesc Psychiatry. 1993;32(4):814-21.

20. Mick MA, Telch MJ. Social anxiety and history of behavioral inhibition in young adults. J Anxiety Disord. 1998;12(1):1-20.

21. Van Ameringen M, Mancini C, Oakman JM. The relationship of behavioral inhibition and shyness to anxiety disorder. J Nerv Ment Dis. $1998 ; 186(7): 425-31$

22. Hayward C, Killen JD, Kraemer HC, Taylor CB. Linking self-reported childhood behavioral inhibition to adolescent social phobia. J Am Acad Child Adolesc Psychiatry. 1998;37(12):1308-16.

23. Schwartz CE, Snidman N, Kagan J. Adolescent social anxiety as an outcome of behavioral inhibition in childhood. J Am Acad Child Adolesc Psychiatry. 1999;38(8):1008-15.

24. American Psychiatric Association. Diagnostic and Statistical Manual of Mental Disorders (DSM-IV). 4th ed. Washington, DC: APA Press; 1994.

25. Sheehan DV, Lecrubier $Y$, Sheehan $\mathrm{KH}$, Amorin $\mathrm{P}$, Janavs J, Weiller E, et al. The Mini-International Neuropsychiatric Interview (M.I.N.I.): the development and validation of a structured diagnostic psychiatric interview for DSM-IV and ICD-10. J Clin Psychiatry. 1998;59(2):22-33.

26. Amorin P. Mini International Neuropsychiatric Interview (MINI): Validation of a short structured diagnostic psychiatric interview. Rev Bras Psiquiatr. 2000;22(3):106-15.

27. Orvaschel H, Puig-Antich J. Schedule for affective disorder and schizophrenia for school age children: epidemiologic version (K-SADSE). 4th ed. Pittsburg, PA: Western Psychiatric Institute and clinic; 1987.

28. Herjanic B, Reich W. Development of a structured psychiatry interview for children: agreement between child and parent on individual symptoms. J Abnorm Child Psychol. 1982;10(3):307-24.

29. Reznick JS, Hegeman JM, Kaufman ER, Woods SW, Jacobs M. Retrospective and concurrent self-report of behavioral inhibition and their relation to adult mental health. Dev Psychopathol. 1992;4:301-21.

30. Biederman J, Hirshfeld-Becker DR, Rosenbaum JF, Herot C, Friedman D, Snidman N, et al. Further evidence of association between behavioral inhibition and social anxiety in children. Am J Psychiatry. 2001;158(10):1673-9.

31. Pine DS, Cohen P, Gurley D, Brook J, Ma Y. The risk for earlyadulthood anxiety and depressive disorders in adolescents with anxiety and depressive disorders. Arch Gen Psychiatry. 1998;55(1):56-64.

32. American Psychiatric Association. Diagnostic and Statistical Manual of Mental Disorders (DSM-III-R). 3rd ed. rev. Washington, DC: APA Press; 1987.

33. Almeida-Filho N, Mari JJ, Coutinho E, França JF, Fernandes F, Andreoli SB, et al. Brazilian multicentric study of psychiatric morbidity. Methodological features and prevalence estimates. $\mathrm{Br} \mathrm{J}$ Psychiatry. 1997;171:524-9. 